\title{
Evidence of impaired cartilage/bone turnover in patients with active ankylosing spondylitis
}

Wilhelm Marhoffer, Hilmar Stracke, Ibrahim Masoud, Monika Scheja, Volkmar Graef, Wolfgang Bolten, Konrad Federlin

\begin{abstract}
Objectives-To compare serum markers of bone formation with the urinary excretion of pyridinium crosslinks (PYR) as a possible measure of bone and cartilage degradation which would detect changes in bone metabolism in patients with ankylosing spondylitis (AS) and to relate them to influences of inflammatory disease activity, and to treatment.

Methods-In 62 patients with AS, serum osteocalcin, alkaline phosphatase (ALP), and skeletal ALP isoenzyme levels were evaluated concurrently in comparison with urinary excretion of pyridinium cross links and were compared with values in $\mathbf{5 0}$ healthy controls.
\end{abstract}

Results-Osteocalcin concentrations in AS patients were in the middle normal range $(3.5(S D 1.2) \mathrm{ng} / \mathrm{ml})$ and did not differ significantly from those in control subjects $(4 \cdot 2(1.3) \mathrm{ng} / \mathrm{ml})$; the same was true for ALP and skeletal ALP isoenzyme fraction (AS: ALP $149(50 \cdot 3)$ U/, skeletal ALP $12.8(4 \cdot 1) \mu g / 1$; controls: ALP 133 $(25 \cdot 2)$ U/, skeletal ALP $11 \cdot 9(4 \cdot 3) \mu g / 1)$. The urinary levels of PYR in AS $(51 \cdot 2$ $(25 \cdot 2)$ nmol PYR/mmol creatinine) were significantly increased compared with controls (33.9 (12.4) nmol PYR/mmol creatinine $(p<0.001))$. In the AS group there was a positive correlation between urinary excretion of PYR and inflammatory disease activity (erythrocyte sedimentation rate (ESR) $(r=0.6$, $\mathrm{p}<0.0001$ ) and $\mathrm{C}$ reactive protein (CRP) $(r=0 \cdot 3, p=0 \cdot 02)$, but no significant correlation was found with ESR, CRP, and markers of bone formation.

Clinic of
Rheumatology
Wiesbaden II,
University of Giessen,
Giessen, Germany
W Marhoffer
I Masoud
W Bolten
Medical Clinic III and
Policlinic
H Stracke
M Scheja
K Federlin
Institute of Clinical
Chemistry and
Pathobiochemistry
V Graef
Correspondence to:
Dr W Marhoffer,
Clinic of Rheumatology
Wiesbaden II,
Leibnizst 23,
65191 Wiesbaden,
Germany.
Accepted for publication
24 March 1995

Conclusions-Bone metabolism in patients with AS is characterised by normal bone formation and enhanced cartilage/bone degradation, suggesting that impaired bone turnover is pronounced in active disease. The results clearly indicate that this comparison can be used to demonstrate impairment of cartilage/bone metabolism which correlates with disease activity. The data obtained further emphasise the importance of measuring both serum variables and urinary excretion of PYR crosslinks to obtain adequate evaluation of cartilage/bone metabolism in patients with AS.

(Ann Rheum Dis 1995; 54: 556-559)
The periarticular and generalised osteoporosis seen in patients with inflammatory rheumatic disease (for example rheumatoid arthritis (RA)) is well recognised, and there is increasing evidence that patients with ankylosing spondylitis (AS) have a certain degree of osteopenia. ${ }^{1-5}$ What remains controversial is the aetiology of this osteopenia: the mechanisms leading to vertebral osteoporosis in AS are poorly understood. In recent years there has been considerable interest in noninvasive methods for monitoring bone metabolism; these offer advantages for screening studies or for repeated monitoring of treatment. Bone metabolism is characterised by two contrasted activities - the formation of new bone by osteoblasts, and the degradation (resorption) of old bone by osteoclasts. ${ }^{6}$

The rate of bone formation and degradation of the bone matrix have usually been measured by alkaline and acid phosphatase activity, hydroxyproline, or other collagen related substances released into the circulation, but though these markers have been widely used, they have certain limitations. ${ }^{6-8}$

In recent years osteocalcin, the major noncollagenous protein of bone, has been regarded as a very sensitive and specific marker of bone formation $^{9}$ and seems to have the advantage of revealing changes in bone formation in patients with active RA. ${ }^{10-12}$ Data on bone formation in patients with $A S$, in contrast to RA, seem to indicate a reduction of bone turnover as a result of decreased bone formation, ${ }^{3}{ }^{13}$ but there is no information on the activity of the disease process.

To gain a more sensitive and specific index of cartilage and bone breakdown, assays for the pyridinium crosslinks of collagen have recently been developed, offering substantial advantages over urinary hydroxyproline estimations, which are non-specific and insensitive. ${ }^{14}$ 15 Pyridinoline (PYR) and deoxypyridinoline (D-PYR) are two nonreducable crosslinks of collagen molecules that result from a post-translational modification within the extracellular matrix and are released and excreted in urine as bone collagen is degraded by osteoclasts. ${ }^{16}$ In this study the PYR compound was investigated.

The aim of this study was to compare serum parameters of bone formation with the urinary excretion of pyridinium crosslinks (as a measure of bone and cartilage degradation) as a means of detecting changes in bone metabolism in patients with AS, and to relate them to treatment and influences of the inflammatory disease process. 
Patients and methods

The study was approved by the University of Giessen ethics committee, and all participants gave informed consent.

The study group consisted of a total of 62 consecutive inpatients and outpatients with AS (mean disease duration 13.3 years (range 1-34)) attending the Clinic of Rheumatology II Wiesbaden, and the Department of Rheumatology, Medical Clinic III and Policlinic at the University of Giessen from 1 September 1992 to 30 September 1994. A control group comprised 50 healthy subjects.

The 13 women (mean age 39.7 years (range 25-60) and 49 men (mean age $41 \cdot 3$ years (range 25-59)) with AS all had characteristic physical signs and radiological (bilateral sacroiliitis) features according to the modified New York criteria. ${ }^{17}{ }^{18}$ None of the AS patients received corticosteroids; 12 had no medication; 14 were taking diclofenac $\leqslant 100 \mathrm{mg} /$ day; 22 patients received indomethacin/acemethacine or proglumethacine $\leqslant 100 \mathrm{mg} /$ day; three were taking ibuprofen $\leqslant 1200 \mathrm{mg} /$ day; five were taking piroxicam $20 \mathrm{mg} /$ day; five were taking acetylsalicylic acid; three were receiving other analgesics. Mean erythrocyte sedimentation rate (ESR) was $27(16) \mathrm{mm} / 1 \mathrm{st} \mathrm{h}$ and mean CRP 20 (17) mg/l (range 5-83 mg/l). Twenty three had pronounced signs of systemic inflammation: ESR $\geqslant 30 \mathrm{~mm} / 1 \mathrm{st} \mathrm{h}$; C reactive protein (CRP) $15 \mathrm{mg} / \mathrm{l}$ or greater; morning stiffness lasting 60 minutes or more at the time of examination. All the AS patients were positive for HLA B27.

The control group ( 31 men, mean age $41 \cdot 3$ years (range 27-56) and 19 women, mean age 41.5 years (range 28-59)) had no evidence of skeletal abnormalities by routine physical and biochemical evaluation, and were receiving no treatment which might alter bone mineral metabolism.

In all female patients and control subjects, the menopausal status was not determined.

Fasting venous blood samples were taken from each subject and the serum extracted and stored at $-20^{\circ} \mathrm{C}$ until required for assay. Serum osteocalcin concentrations were determined in duplicate by a commercial radioimmunoassay kit (Immuno-Nuclear Corporation, Stillwater, MN, USA). The sensitivity of the assay was $0 \cdot 2$ $\mathrm{ng} / \mathrm{ml}$. In all cases the intra-assay variation was less than $8 \%$ and the interassay variation less than $10 \%$.

Total alkaline phosphatase (ALP) activity (a parameter used in screening to assess skeletal disease) was determined by a routine method. ${ }^{19}$ For greater specificity, serum skeletal ALP isoenzyme levels were detected with the Tandem-R-Ostase ${ }^{(\mathrm{TM})}$ Immunoradiometric Assay (Hybritech Europe, Liege, Belgium), with an estimated minimum detectable concentration of $2 \cdot 0 \mu \mathrm{g} / \mathrm{l}$. The within-run precision obtained was $3 \cdot 7-6 \cdot 7 \% \quad(\mathrm{CV} \%)$; between-run precision was $7 \cdot 0-8 \cdot 1 \%(\mathrm{CV} \%)$, depending on serum concentrations. ${ }^{20}$ Preliminary data were obtained and compared with skeletal ALP isoenzymes separated by electrophoresis on agarose gel membranes
(Paragon Isopal ${ }^{(\mathrm{TM})}$, Beckmann Instruments, Munich, Germany).

PYR was measured in fasting urine specimens and corrected for creatinine excretion with the Collagen Crosslinks Elisa $^{(\mathrm{TM})}$ (Metra Biosystems Inc). This competitive enzyme immunoassay measures urine crosslinks using a monoclonal antibody against PYR. Cross reactivity is $40 \%$ with free D-PYR and less than $2 \%$ with amino acids or large PYR peptides $(>1000 \mathrm{Da})$. The immunoassay requires no acid hydrolysis and exhibits a sensitivity of $25 \mathrm{nmol} / \mathrm{PYR}$, an intra-assay variation of $<10 \%$, and an interassay variation of $<15 \%$. $^{21}$

Routine blood haematology measurements were made with a Coultercounter ${ }^{(\mathrm{TM})}$ at the Medical Clinic III and Policlinic, University of Giessen. CRP was determined by laser nephelometry (Behring, Marburg, Germany), and agglutinating rheumatoid factors (RF) were identified with the latex fixation and Waaler Rose tests. Serum calcium was determined by atomic absorption spectrometry, and serum phosphate, fasting urinary calcium, and urinary phosphate by routine laboratory procedures. Westergren's method was used for ESR.

\section{STATISTICAL ANALYSIS}

All results are expressed as mean (SD). Statistical significance was estimated by Student's $t$ test. Analysis of variance was performed and, where appropriate, simple regression analysis (in co-operation with the Institute of Medical Information Sciences, University of Giessen). Values of $p$ exceeding 0.05 were considered non-significant.

\section{Results}

Serum concentrations of osteocalcin were in the middle normal range for patients with AS $(3.5(1.2) \mathrm{ng} / \mathrm{ml})$ and did not differ significantly from those in healthy controls $(4 \cdot 2$ $(1 \cdot 3) \mathrm{ng} / \mathrm{ml}$ ). Serum ALP (normal range for men 60-170 U/l and for women 40-160 U/l) was not significantly different between AS patients $(149(50 \cdot 3) \mathrm{U} / \mathrm{l})$ and controls (133 (25.3) U/1). Skeletal ALP isoenzyme fraction also did not differ significantly between AS patients $(12.8(4 \cdot 1) \mu \mathrm{g} / \mathrm{l})$ and controls (11.9 $(4 \cdot 2) \mu \mathrm{g} / 1)$. No statistically significant correlation was found between markers of bone formation and inflammatory disease activity.

Markedly enhanced urinary pyridinium crosslink excretion was detected in patients with AS (51.2 (25.2) nmol PYR/mmol creatinine) compared with control subjects (33.9 (12.3) $\mathrm{nmol} \mathrm{PYR} / \mathrm{mmol}$ creatinine) $(p<0.001)$, but there was no significant difference between the groups in urine excretion of calcium (AS $3 \cdot 7(1 \cdot 8) \mathrm{mmol} / 1$; control $3.3(0.8) \mathrm{mmol} / \mathrm{l})$.

In the AS patient group there was a positive correlation for urinary excretion of PYR and inflammatory disease activity (ESR) $(r=0.6$, $\mathrm{p}<0.0001)$ and CRP $(r=0.3, \mathrm{p}<0.02)$ (figs $1,2)$. 


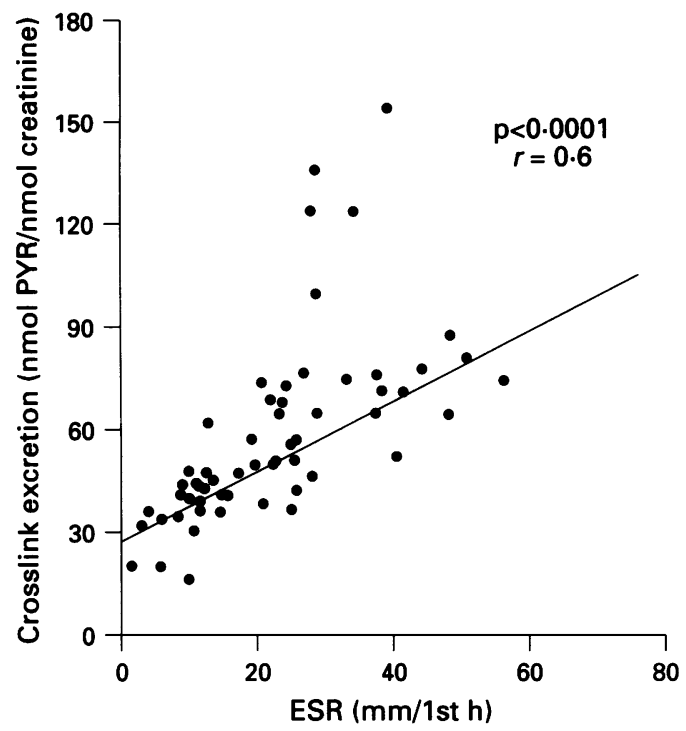

Figure 1 Linear relationship between inflammatory disease activity (erythrocyte sedimentation rate (ESR)) and urinary excretion of pyridinium crosslinks (expressed as amount of pyridinium (PYR) excreted, corrected for creatinine excretion) in patients with ankylosing spondylitis $(r=0.6, p<0.0001)$.

Urinary concentrations of PYR in patients with AS were not related to age, gender, disease duration, serum calcium, or urinary calcium excretion. There was no significant difference in urinary crosslink excretion between patients treated or not treated with non-steroidal anti-inflammatory drugs (NSAIDs) (data not shown).

\section{Discussion}

Bone loss leading to generalised osteoporosis is a well recognised extra-articular manifestation of rheumatoid arthritis and patients with AS are likely to develop certain degrees of osteopenia; thus, clinically, vertebral osteoporosis is a common feature. The cellular mechanisms leading to this bone loss, however,

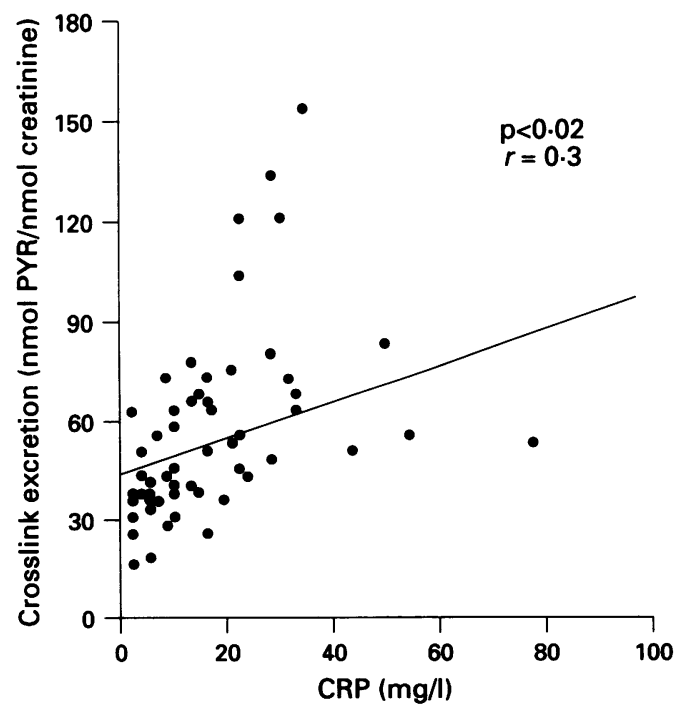

Figure 2 Linear relationship between inflammatory disease activity as measured with $C$ reactive protein (CRP) and urinary excretion of pyridinium crosslinks (expressed as amount of pyridinium (PYR) excreted, corrected for creatinine excretion) in patients with ankylosing spondylitis $(r=0.3, p=0.02)$. are not well understood. ${ }^{35}$ In AS, few data exist concerning bone turnover, and decreased concentrations of serum osteocalcin have been found, suggesting low osteoblastic activity and bone formation. ${ }^{51322}$ In this study, we investigated bone metabolism in AS patients by measuring concurrently the bone formation markers osteocalcin, ALP and skeletal ALP, in comparison with the urinary excretion of pyridinium crosslinks as a promising marker of cartilage and bone resorption. The data obtained revealed that the markers of bone formation in AS patients were not statistically different from those of control subjects, indicating a normal rate of bone formation in these patients. These data contrasted with recently published findings by Franck $e t$ al, of decreased serum concentrations of osteocalcin, suggesting decreased bone formation. ${ }^{22}$ In that study, ESR was reported not to be increased, except in two patients receiving NSAIDs. ${ }^{22}$ Thus the differences between our findings and those of Franck's group might be explained, at least in part, by patient selection and treatment.

The present data on urinary PYR crosslinks excretion showed increased values for patients with AS, suggesting increased cartilage and bone catabolism in this condition, which supports former studies indicating that AS, in particular, might be associated with vertebral osteopenia (related to the inflammation site) and with generalised bone loss, leading eventually to clinically apparent osteoporosis. ${ }^{23}$ This last outcome might be related to factors such as disease duration and activity, functional impairment, menopausal status, concomitant medications, diet, and age at onset of ankylosing spondylitis. Our data support the concept that inflammatory disease activity might alter cartilage/bone metabolism. ${ }^{11} 1224$

It is well established that pyridinium is the major crosslink in cartilage collagens, and articular cartilage is known to contain the greatest concentrations of PYR. ${ }^{21}$ Thus the high levels of urinary PYR observed particularly in active AS could be regarded as reflecting degradation of cartilage matrix, leading to articular impairment. With regard to influences of drug regimens on bone metabolism (that is, on urinary excretion of PYR), it is interesting to note that, in patients with AS treated with either NSAIDs or no medication, no differences in concentrations of PYR were found, suggesting no significant effect of NSAID treatment on cartilage/bone metabolism with the doses administered.

In conclusion, our data obtained by measuring pyridinium crosslinks demonstrated impairment of cartilage/bone metabolism in patients with AS, which correlated with the disease activity. The results suggest further that inflammation could lead to locally occurring bone resorption, in addition to, finally, clinically detectable osteopenia or generally osteoporosis.

The data gave evidence, furthermore, of the advantage of measuring urinary PYR excretion in comparison with markers of bone formation 
(osteocalcin, skeletal ALP) for evaluating cartilage and bone metabolism in AS. These findings emphasise the importance of measuring simultaneously the serum parameters of bone formation and the urinary excretion of pyridinium crosslinks as a marker of cartilage/bone degradation. These will allow assessment of cartilage and bone turnover in active spondyloarthropathic disease to be considered in further studies.

The authors wish to acknowledge the statistical advice of $\mathbf{M r}$ W Pabst, Institute of Medical Information Sciences, University of Giessen.

1 Helfgott S, Rosenthall L, Esdaile J, et al. Generalized skeletal response to $99 \mathrm{~m}$ technetium methylene diphosphonate in rheumatoid arthritis. $\mathcal{F}$ Rheumatol 1982; 9: $939-41$

2 Kennedy A C, Lindsay R. Bone involvement in rheumatoid arthritis. Clin Rheum Dis 1977; 3: 403-20.

3 Hanson C A, Shagrin J W, Duncan H. Vertebral osteoporosis in ankylosing spondylitis. Clin Orthop 1971; 74: 59-64.

4 Patton J T. Differential diagnosis of inflammatory spondylitis. Skeletal Radiol 1976; 1: 77-90.

5 Ralston S R, Urqhart G K, Brezeski M, et al. Prevalence of vertebral compression fractures due to osteoporosis in ankylosing spondylitis. $B M 7$ 1990; 300: 563-5.

6 Delmas P D. Biochemical markers of bone turnover. $f$ Bone Miner Res 1993; 8 (suppl 2): 549-55.

7 Kivorikko K I. Excretion of urinary hydroxyproline. In: Frame B, Potts J T, eds. Clinical disorders of bone and mineral metabolism. Amsterdam: Excerpta Medica, 1983; 105.

8 Whyte P M. Alkaline phosphatase and the measurement of bone formation. In: Frame B, Potts J T, eds. Clinical disorders of bone and mineral metabolism. Amsterdam: Excerpta Medica, 1983; 120-32.
9 Price P A, Parthemore J G, Deftos L J. New biochemical marker for bone metabolism. F Clin Invest 1980; 66: 878-83.

10 Slovik D M, Gundberg R, Neer M, et al. Clinical evaluation of bone turnover by serum osteocalcin measurements in a hospital setting. $¥$ Clin Endocrinol 1984; 59: 228-30.

11 Magaro M, Altomonte L, Mirone $\mathrm{L}$, et al. Bone GLA protein (BGP) levels and bone turnover in rheumatoid protein (BGP) levels and bone turnover
arthritis. Br f Rheumatol 1989; 28: 207-11.

12 Marhriter Wr, Schatz H, Stracke H, et al. Serum osteocalcin levels in rheumatoid arthritis: A marker for accelerated bone turnover in late onset rheumatoid arthritis. $f$ bone turnover in late onse
Rheumatol 1991; 8: 1158-92.

13 Will R, Palmer R, Bhalla A K, et al. Osteoporosis in early ankylosing spondylitis: a primary pathological event. Lancet 1989; ii: 1483-7.

14 Robins S P. An enzyme-linked immuno-assay for the collagen crosslink pyridinoline. Biochem $f$ 1982; 207: 617-20.

15 Black D, Duncan A, Robins S P. Quantitative analysis of the pyridium crosslinks of collagen in urine using ionpaired reversed-phase high performance liquid paired reversed-phase high performance liquil

16 Fujimoto D, Moriguchi T, Ishida T, et al. The structure of pyridinoline, a collagen crosslink. Biochem Biophys Res Commun 1978; 84: 52-7.

17 Moll J M H, Wright V. New York clinical criteria for ankylosing spondylitis. A statistical evaluation. Ann Rheum Dis 1973; 32: 354 .

18 Khan M A, van der Linden S M. Ankylosing spondylitis and other spondylarthropathies. Rheum Dis Clin North Am 1990; 16: 551 .

19 Harris $H$. The human alkaline phosphatases: what we know and what we don't know. Clin Chim Acta 1989; 186: 133.

20 Fishman W H. Alkaline phosphatase isoenzymes: recent progress. Clin Biochem 1990; 23: 99-104.

21 Robins S P, Stewart P, Astbury C, et al. Measurements of the crosslink compound pyridinoline in urine as an index of collagen degradation. Ann Rheum Dis 1986; 45: 969-73.

22 Franck $H$, Keck E. Serum osteocalcin and vitamin D metabolites in patients with ankylosing spondylitis. Ann Rheum Dis 1993; 52: 343-6.

23 Reid D, Jermy J, Norman S J, et al. Bone mass in ankylosing spondylitis. F Rheumatol 1986; 13: 932-6.

24 Sheehan N J, Slavin B M, Kind P R N, et al. Increased serum alkaline phosphatase activity in ankylosing spondylitis. Ann Rheum Dis 1988; 47: 563-5. 